SOI: $1.1 /$ TAS $\quad$ DOI: $10.15863 /$ TAS International Scientific Journal Theoretical \& Applied Science

p-ISSN: 2308-4944 (print) $\quad$ e-ISSN: 2409-0085 (online)

Year: $2015 \quad$ Issue: $11 \quad$ Volume: 31

Published: $30.11 .2015 \quad \underline{\text { http://T-Science.org }}$

SECTION 31. Economic researches, finance, innovations, risk management.
Valery Safarbiyevich Misakov

Dr.Econ.Sci., professor, head of department "Forecasting and sustainable regional development" Institute of informatics and problems of regional government of the Kabardino-Balkarian Russian Academy of Sciences scientific center, Russia MBC@@mail.ru

Anzor Valeryevich Misakov Cand.Econ.Sci., the associate professor "Accounting" FGBOOU WAUGH "The Kabardino-Balkarian state agricultural university of V. M. Kokov", Russia Misakov85@mail.ru

\title{
SOME FEATURES OF SYSTEM OF CRISIS MANAGEMENTAS FACTOR OF NEED OF JUSTIFICATION OF SYSTEM DEVELOPMENT OF ECONOMIC ENTITIES OF AGRARIAN AND INDUSTRIAL COMPLEX
}

\begin{abstract}
In article problems of the organization of system of crisis management are considered. Institutional approach to justification of system development of economic entities of agrarian and industrial complex is offered.

Key words: Crisis management, system development, economic entity, agro-industrial complex

Language: Russian

Citation: Misakov VS, Misakov AV (2015) SOME FEATURES OF SYSTEM OF CRISIS MANAGEMENTAS FACTOR OF NEED OF JUSTIFICATION OF SYSTEM DEVELOPMENT OF ECONOMIC ENTITIES OF AGRARIAN AND INDUSTRIAL COMPLEX. ISJ Theoretical \& Applied Science 11 (31): 130-134.

Soi: http://s-0-i.org/1.1/TAS-11-31-20 Doi: crossef http://dx.doi.org/10.15863/TAS.2015.11.31.20

\section{НЕКОТОРЫЕ ОСОБЕННОСТИ СИСТЕМЫ АНТИКРИЗИСНОГО УПРАВЛЕНИЯ КАК ФАКТОР НЕОБХОДИМОСТИ ОБОСНОВАНИЯ СИСТЕМНОГО РАЗВИТИЯ ХОЗЯЙСТВУЮЩИХ СУБЪЕКТОВ АПК}

Аннотация: В статье рассмотрены проблемы организациии системы антикризисного управления. Предложен институциональный подход к обоснованию системного развития хозяйствуюших субъектов АПК.

Ключевые слова: Антикризисное управление, системное развитие, хозяйствуюший субъект, агропромышленный комплекс.
\end{abstract}

Организация системы антикризисного управления строится на задействовании разных подходов, в частности, комплексный подход (здесь учитываются все управленческие аспекты и их взаимосвязь); интегральный подход (здесь исследуются все процессы (по вертикали и по горизонтали)); динамический воспроизводственный и другие подходы, что придает системе большую гибкость и расширяет возможности к диверсификации $[1,7,17]$.

Систему антикризисного управления необходимо организовать в таком виде, чтобы она стимулировала создание условий для адекватной реакции на преобразования окружающей и внутренней среды, так как это позволит расширить спектр отбора вариантов поведения в кризисной ситуации. Такой подход позволит разрабатывать и принимать эффективные управленческие решения, формировать стратегические ориентиры и цели, разрабатывать инновационные программы, реализовывать инвестиционные проекты. Текущие проблемы и условия организации антикризисного управления вызывают необходимость формирования особого механизма управления, учитывающего особую мотивацию антикризисной деятельности [12].

Специалисты указывают на необходимость рационального сочетания стратегии и тактики антикризисного управления. Действительно, стратегические решения по предотвращению кризиса необходимо разрабатывать, принимать и реализовывать еще на ранних стадиях управления, когда движение предприятия к кризисному положению еще не носит кумулятивного характера, то есть он еще не стал 
необратимым. Вместе с тем, управленческие решения, принимаемые на ранних стадиях, построены, как правило, на оперативной неполной информации, что может дать иные конечные результаты $[1,5,6,13]$. На практике, как правило, управленцы испытывают жесткий цейтнот, в связи с чем, времени для тщательного анализа с целью предотвращения кризиса либо мало, либо совсем нет. Поэтому, в подобных случаях управленцы на основе оперативного анализа пытаются предпринять шаги по нейтрализации кризисных симптомов, которые еще возможно осуществить в кратчайший период времени $[14,16]$.

Многочисленные тактические мероприятия по выводу предприятия из кризисного состояния можно систематизировать в две группы: защитные и наступательные.

Мероприятия первой группы построены на реализации сберегающих мер. Как правило, они применяются при нежелательных стечениях внешних обстоятельств. Защитная тактика проводится в рамках оперативных мероприятий, таких как ликвидация убытков, уменьшение расходов, выявление внутренних резервов, ротация кадров и т.д..

Поддерживая основное производство на плаву, защитная тактика дает возможность мобилизации всех ресурсов. Вместе с тем, она также может привести к уменьшению производственных объемов по другим видам деятельности $[8,11]$.

Естественно, когда уже отчетливо видны все симптомы кризиса, гораздо легче разрабатывать и принимать необходимые меры для его нейтрализации, в частности, ликвидация нерентабельных видов производств, реструктуризация задолженности, договоренность об отсрочке платежей, диверсификация производства, сокращение и набор новых управленцев, ежедневный маркетинговый анализ, фин.поддержка от партнеров и другие меры $[2,5,8,15]$.

Наступательная тактика является более предпочтительной и эффективной, для нее характерно задействование мероприятий стратегического порядка. При ее использовании, помимо ресурсосберегающих мероприятий, организовываются маркетинговые исследования, анализируются новые рынки с целью выхода и захвата, происходит модернизация и техническое перевооружение предприятия. При этом, систематически на предприятии проводят комплексный анализ с целью оценки складывающейся ситуации и внесения необходимых корректировок в деятельности предприятия [16].

Стратегические мероприятия состоят в исследовании положения макро- и микросреды и разработке новой производственной и маркетинговой политики предприятия; в совершенствовании использования организационно-экономического механизма образования кризисных ситуаций; создании системы мониторинга окружающей и внутренней среды предприятия с целью предвидения симптомов приближающегося кризиса; разработки концепции санации предприятия [4, 7, 9].

Началом антикризисного управления можно считать момент выбора миссии предприятия, разработки концепции и цели его планируемой деятельности [3, 4, 8].

На сегодня уже имеется с десяток различных стратегий антикризисного управления, в том числе:

- стратегия профилактики кризисной ситуации (ее применение в большей части зависит от возможностей адекватного распознавания кризисных симптомов, умения оперативно анализировать их характер и тенденции;

- стратегия выжидания созревания кризиса (она применяется при наступлении кризисов очистительного типа, после которого ждут возможностей реализации необходимых нововведений, рождаемых этим кризисом);

- стратегия противодействия кризисным явлениям (данная стратегия не всегда рациональна в виду того, что немало обстоятельств, когда целесообразно отодвинуть кризис во времени);

- стратегия стабилизации ситуации (она применяется в тех случаях, когда достаточно задействовать дополнительные ресурсы);

- стратегия просчитанного риска (ее применение нейтрализует последствия кризиса).

Соотношение окружающей и внутренней среды формируется присутствием интеграционных взаимосвязей между хозяйствующими субъектами агропромышленного производства. При этом, осуществляется процесс типа «действиереакция», формирующий эволюционную основу для комплексного развития предприятий АПК в виде переходного положения от анархичной совокупности субъектов (конгломерат) к целенаправленной, упорядоченной и организованной системе [7, 8]. Стратегия комплексного развития хозяйствующих субъектов аграрной сферы показывает взаимосвязь и взаимообусловленность производственных структур АПК в процессе формирования конкурных продуктов. Целесообразность формирования интеграционной системы является необходимым фактором образования социо-экологоэкономической системы. 
Анализ развития сложных социо-экологоэкономических систем, в том числе - системы агропромышленной интеграции, осуществляется в рамках общей теории систем, кибернетики, специальных теориях систем [2, 3, 9].

При исследовании социо-экологоэкономических систем необходимо принимать во внимание характерные черты этих систем:

- синергичность системы - это означает, что эффективность деятельности системы превышает сумму эффективности деятельности ее участников);

- сложность системы (здесь большое количество участников, особые трудности взаимодействия между участниками; сложные функции, необходимость постоянного учета большого количества стохастических факторов окружающей среды);

- иерархичность (система рассматривается как составляющая часть более высокого порядка);

- открытость (постоянная взаимосвязь с внешней средой);

- полиструктурность (наличие разноуровневых взаимопереплетенных систем);

- целостность (различные интересы участников посредством интеграции объединяются в единое целое).

Во многих работах термин «интеграционная связь» воспринимают в данном контексте идентично понятию «синергетическая связь» [5, 13]. Интеграционные связи между хозяйствующими субъектами являются основой проявления эмерджентных свойств, то есть свойств полной системы, которой не обладают ее элементы - участники агропромышленных структур, рассматриваемых вне системы.
Исследователи в качестве эмерджентных свойств социо-эколого-экономической рассматривают: возможности наращивания производства, увеличение эффективности применяемых ресурсов, уменьшение производственных издержек, рост качества продукции, возможности привлечения инвесторов... Свою нишу, при этом, занимает исследование формирования социальной инфраструктуры интегрированных хозяйствующих субъектов АПК, ибо обособленные предприятия не могут содержать на своем балансе жилые дома, санатории, поликлиники и т.п.

При анализе формирования интеграционных связей в АПК надо учитывать, что государственное регулирование на интеграционный процесс в агропромышленном производстве должно быть направлено на достижение благоприятных экономических условий, позволяющих устойчиво развиваться комплексу агропромышленной интеграции. Для этого должны быть задействованы разнообразные экономические методы, в том числе, прямая господдержка сельскохозяйственных товаропроизводителей; протекционистская ценовая политика, налоговые льготы и т.п. и самое главное - государственные структуры должны стать не надзирающими органами, а равноправными партнерами интеграции.

Социо-эколого-экономическая система, как и любая система, развивается в противоречиях. Процесс развития хозяйствующих субъектов АПК также является сложным набором противоречий, которые представлены в таблице 1 .

\section{Таблица 1}

Противоречия комплексности развития хозяйствующих субъектов АПК.

\begin{tabular}{|l|l|}
\hline \multicolumn{1}{|c|}{ Противоречие } & \multicolumn{1}{|c|}{ Характеристика } \\
\hline $\begin{array}{l}\text { 1. Между разделением труда в } \\
\text { рамках технологической цепи } \\
\text { производства продукции и } \\
\text { увеличение ее целостности }\end{array}$ & $\begin{array}{l}\text { Наблюдаются закономерные «дробления» технологической цепи } \\
\text { произодства сельхозпродукции на отдельные стадии. Появляются } \\
\text { современные специализированные предприятия. Создается новая система }\end{array}$ \\
\hline $\begin{array}{l}\text { 2. Между разделением и } \\
\text { интеграцией труда }\end{array}$ & Выход единичного разделения труда за рамки предприятия АПК. \\
\hline $\begin{array}{l}\text { 3. Между крупными и малыми } \\
\text { предприятиями }\end{array}$ & $\begin{array}{l}\text { Для крупных предприятий характерны массовые стандарты, предприятия } \\
\text { Малого бизнеса оперативны, гибки, удовлетворяют серийные запросы. } \\
\text { вместе с тем, их взаимосочетание вырабатывает новые положительные }\end{array}$ \\
\hline
\end{tabular}




\begin{tabular}{|c|c|}
\hline $\begin{array}{l}\text { 4. Между частными } \\
\text { интересами отдельных } \\
\text { предприятий и общими } \\
\text { целями системы }\end{array}$ & $\begin{array}{l}\text { У каждого обособленного участника технологической цепи АПП свои } \\
\text { собственные интересы (по производству, по реализации, по конечным целям } \\
\text { и т.д.). } \\
\text { Вместе с тем, реализация этих интересов возможна при совместной } \\
\text { деятельности в рамках технологической цепи. }\end{array}$ \\
\hline $\begin{array}{l}\text { 5. Между самостоятельностью } \\
\text { участника и единством с } \\
\text { другими участниками системы } \\
\text { агропромышленной } \\
\text { интеграции }\end{array}$ & $\begin{array}{l}\text { Самостоятельность состоит в том, что любой участник выполняет особые } \\
\text { только ему присущие функции. } \\
\text { Однако, реализовывать свои специфические функции предприятие может } \\
\text { лишь в рамках системы агропромышленной интеграции. }\end{array}$ \\
\hline
\end{tabular}

Противоречия являются основой развития, когда они исчезают, это означает, что система перешла на качественно новый уровень, который, в том числе, характеризуется новой степенью целостности составляющих ее структур. В ином случае, мы не сможем видеть интеграцию участников создания агропромышленной продукции $[1,10,14]$.

В ходе своего развития социо-экологоэкономическая система проходит кризисное состояние, движение системы довольно часто является неустойчивым, ибо на нее воздействуют определенные факторы, способные менять ее поведение. Однако, это всегда может сопровождаться синергетическим эффектом, который проявляется в сходе системы с линейной траектории, в резком (катастрофическом) увеличении или уменьшении каких-либо свойств $[4,6,12]$.

Свойства системы можно трактовать при помощи закона синергии: для каждой системы имеется определенный набор входящих в нее подсистем, причем, ее потенциал всегда может быть значимо больше простой суммы потенциалов ее подсистем или значительно меньше. Поэтому, это понятие довольно часто называют эффектом «2+2=5», чтобы подчеркнуть, что предприятие, в поиске определенных комбинаций всех видов ресурсов, в коих эффект от суммы будет больше, чем сумма составляющих частей. При этом, возникает дополнительный эффект $(1-5=-4)$, который обусловлен синергизмом.

Надо иметь в виду, что синергетический эффект способен разнонаправлено воздействовать на развитие социо-экологоэкономической системы: как прогрессивно созидая, так и отрицательно, неся собой разрушение. Причем, в ходе положительного развития социо-эколого-экономической системы на смену этапу взаимодействий приходит этап объединенных действий. На последнем этапе хозяйствующие субъекты интеграционных процессов уже не обособленны друг от друга и на этом этапе прежде разрозненные предприятия АПК функционируют как объединенные $[15,16]$.

\section{References:}

1. Abaev RM, Misakov AV, Yeneeva MN (2012) Ocenka resursnogo konteksta i kriterija optimal'noi traektorii yekonomicheskogo rosta regional'noi yekonomiki. Izvestija KabardinoBalkarskogo nauchnogo centra RAN. 2012. №2. pp. 5-11.

2. Bashieva DH, Kumykova ZS, Misakov AV (2015) Nekotorye podhody $\mathrm{k}$ primeneniyu klastera $\mathrm{v}$ ramkah razrabotki i osushestvlenija regional'noi yekonomicheskoi politiki. Izvestija Kabardino-Balkarskogo nauchnogo centra RAN. 2015. № 1(63). pp. 117-122.

3. Bezirova ZH, Misakov VS (2011) Analiz socioyekologo-yekonomicheskogo razvitija dotacionnogo regiona. Yekonomicheskie nauki. 2011. № 85. pp. 131-135.

4. Gerter IK, Misakov AV (2011) Teoreticheskie aspekty issledovanija proizvodstvennoi infrastruktury sel'skih territorii $\mathrm{v}$ social'no orientirovannoi rynochnoi yekonomike. Izvestija Kabardino-Balkarskogo nauchnogo centra RAN. 2011. №2. pp. 47-55.

5. Dzagoeva IT, Mirzoeva AR, Misakov AV (2012) Rol' uchetnoi politiki V sisteme normativnogo regulirovanija buhgalterskogo ucheta i nalogooblozhenija v RF. Terra Economicus. 2012. T. 10. №4-3. pp. 63-66.

6. Kalov ZA, Misakov AV, Teuvazhukov YB (2008) Perehod ot strategii vyzhivanija k 
\begin{tabular}{l|lrl|l|ll} 
& ISRA (India) & $=\mathbf{1 . 3 4 4}$ & SIS (USA) & $=\mathbf{0 . 9 1 2}$ & ICV (Poland) & $=\mathbf{6 . 6 3 0}$ \\
Impact Factor: & ISI (Dubai, UAE) $=\mathbf{0 . 8 2 9}$ & PUHIL (Russia) $=\mathbf{0 . 1 7 9}$ & PIF (India) & $=\mathbf{1 . 9 4 0}$ \\
& GIF (Australia) & $\mathbf{0 . 5 6 4}$ & ESJI (KZ) & $=\mathbf{1 . 0 4 2}$ & & \\
& JIF & $=\mathbf{1 . 5 0 0}$ & SJIF (Morocco) $=\mathbf{2 . 0 3 1}$ & &
\end{tabular}

strategii ustoichivogo razvitija. Fundamental'nye issledovanija. 2008. № 9. pp. 41-46.

7. Kushbokova RH, Shamurzaev ZS, Misakov VS (2009) Nekotorye podhody k upravleniyu innovacionnym potencialom promyshlennogo predprijatija. Terra Economicus. 2009. T. 7. № 4-3. pp. 123-125.

8. Misakov AV, Abdulkadyrova MA, Basaev IB (2008) Ocenka sostojanija analiticheskoi raboty na predprijatijah APK. Nauchno-tehnicheskie vedomosti

Sankt-Peterburgskogo gosudarstvennogo politehnicheskogo
universiteta. Yekonomicheskie nauki. 2008. T. 3-2. № 58. pp. 117.

9. Misakov AV (2011) Konkurentnoinnovacionnyi podhod $\mathrm{k}$ issledovaniyu dejatel'nosti predprijatii APK. Yekonomicheskie nauki. 2011. №85. pp. 172176.

10. Misakov AV (2012) Rynochnoe reformirovanie proizvodstvenno-hozjaistvennyh svjazei $\mathrm{V}$ sisteme APK. Izvestija Kabardino-Balkarskogo nauchnogo centra RAN. 2012. № 3. pp. 141146.

11. Misakov AV, Afov HH (2010) Sistemnyi analiz informacionnogo obespechenija upravlenija monoproduktovymi predprijatijami regional'nogo proizvodstvennogo kompleksa.
Izvestija Kabardino-Balkarskogo nauchnogo centra RAN. 2010. № 5-1. pp. 75-82.

12. Misakov AV, Basaev IB, Berdov HV (2008) Konceptual'naja shema antikrizisnogo upravlenija predprijatiem. Izvestija KabardinoBalkarskogo nauchnogo centra RAN. 2008. №3. pp. 65-69.

13. Misakov AV, Misakova ZV, Bricyna VA (2006) Sovershenstvovanie mehanizma upravlenija korporativnymi strukturami. Terra Economicus. 2006. №4. pp. 80-83.

14. Misakov VS, Kovaleva IN, Misakov AV (2014) Modelirovanie sistemy ustoichivogo razvitija regional'nyh yekonomicheskih klasterov. Nal'chik, 2014.

15. Tleuzhev RM, Misakov AV (2014) Informacionnaja asimmetrija i ee vlijanie na analiz finansovogo sostojanija predprijatii. Izvestija Kabardino-Balkarskogo nauchnogo centra RAN. 2014. № 4(60). pp. 115-120.

16. Chikatueva LA, Totorkulov SM, Misakov VS (2012) Sistemnyi analiz prognoznyh ocenok pokazatelei yeffektivnosti dejatel'nosti predprijatii malogo biznesa. Terra Economicus. 2012. T. 10. №1-3. pp. 137-141.

17. Misakov VF, Baiduyev IZ, Gendugov SZ (2009) Functionally-value analysis as a method of system research. Izvestija Orenburgskogo gosudarstvennogo agrarnogo universiteta. 2009. T. 1. № 22-2. pp. 167-172. 